\title{
Variación de la actividad de lisozima en leche de tres especies de perisodáctilos
}

\author{
Castro, J.F.; Pérez, M.E. \\ Instituto de Fisiología Animal, Fundación Miguel Lillo, Miguel Lillo 251, (4000) San Miguel de Tucumán, \\ Tucumán, Argentina. Tel. 0381-4330516. E-mail: felipecastrobiologo@gmail.com
}

\begin{abstract}
Resumen
Castro, J.F.; Pérez, M.E.: Variación de la actividad de lisozima en leche de tres especies de perisodáctilos. Rev. vet. 25: 1, 58-60, 2014. Se describe por primera vez la existencia de actividad de lisozima en leche de tapir, perisodáctilo perteneciente a nuestra fauna autóctona. La enzima es analizada comparativamente a las actividades en leche de burra y yegua, tanto a $25^{\circ} \mathrm{C}$ como a temperaturas elevadas. Se encontró un comportamiento particular de la enzima a altas temperaturas en leche de burra y de tapir, posibilitando desarrollar una hipótesis acerca de la presencia de un inhibidor de la enzima, lábil al calor, que al desaparecer provocaría el aumento de la actividad de lisozima.
\end{abstract}

Palabras clave: yegua, burra, tapir, lisozima en leche.

\begin{abstract}
Castro, J.F.; Pérez, M.E.: Variation of lysozyme activity in milk of three species of Perissodactyla. Rev. vet. 25: 1, 58-60, 2014. The existence of lysozyme activity in the milk of a native perissodactyle, the tapir, is described. This enzyme is compared to lysozyme activity in asses' and mare's milk, both at $25^{\circ} \mathrm{C}$ as well as at higher temperatures. A particular behavior of the enzyme at high temperatures was found in ass's and tapir's milk, allowing to develop an hypothesis regarding the presence of an enzyme inhibitor, labile to heat, that would cause the increase of the lysozyme activity after destruction/consumption.
\end{abstract}

Key words: mare, ass, tapir, lysozyme in milk.

\section{INTRODUCCIÓN}

La lisozima es una enzima largamente conocida por ser un agente antibacteriano natural. Fue descubierta en 1922 por Alexander Fleming, al comprobar que la secreción nasal poseía la facultad de lisar determinados tipos de bacterias. Cataliza la hidrólisis de enlaces glicosídicos $\beta(1-4)$ entre $\mathrm{N}$-acetilglucosamina y ácido $\mathrm{N}$-acetilmurámico, mucopolisacáridos presentes en la pared celular bacteriana. Bajo determinadas condiciones, esta actividad conduce a la alteración del equilibrio de las funciones de la célula, con dispersión de su contenido. En el laboratorio produce remoción de la turbidez de la suspensión bacteriana ${ }^{9}$.

La enzima está ampliamente distribuida en los seres vivos. En mamíferos se encuentra en varias secreciones, incluyendo la de glándula mamaria. La concentración y actividad de lisozima varían considerablemente en la leche de las diferentes especies, lo cual se relaciona con el mecanismo de defensa inespecífica de esta secreción ${ }^{10}$. La enzima lisa la mayoría de las bacterias Gram positivas y varias Gram negativas y, junto

Recibido: 5 marzo 2014 / Aceptado: 14 abril 2014 a otros factores presentes en la leche que incluyen inmunoglobulinas, lactoferrina y lactoperoxidasa, actúa en el tracto digestivo de las crías para reducir la incidencia de infecciones gastrointestinales ${ }^{1}$.

Dentro del grupo de los perisodáctilos, tanto la leche de yegua (Equus caballus) como la de burra (Equus asinus) han sido estudiadas por razones relacionadas con las propiedades nutricionales y terapéuticas difundidas desde tiempos ancestrales, sobre todo en países de Europa y Asia ${ }^{8,11}$. La leche de burra, por su composición similar a la leche humana, puede ser usada como una alternativa para niños que presentan intolerancia a la leche de vaca ${ }^{2}$. Con respecto a la leche de burra, estudios previos revelaron un contenido de lisozima elevado en comparación a la leche de yegua y de vaca, lo cual sería responsable de su baja concentración bacteriana $^{4,12}$. Asimismo, otros autores sugirieron el uso de la leche de burra con propósitos probióticos, puesto que probó ser un buen medio de crecimiento para cepas de lactobacilos probióticos debido a su elevado contenido de lisozima y lactosa ${ }^{5,6}$.

En tapir (Tapirus terrestris), la otra especie cuya leche se estudia en el presente trabajo, no se hallaron datos bibliográficos previos sobre el contenido y la ac- 
tividad de esta enzima en el lactosuero, como así tampoco estudios sobre la sensibilidad de la misma a las diferentes temperaturas.

El objetivo de la investigación consistió en caracterizar la actividad de lisozima en leche de tapir y analizar comparativamente el comportamiento frente a diferentes temperaturas de la lisozima presente en la leche de tres especies de perisodáctilos: Tapirus terrestris, Equus caballus y Equus asinus.

\section{MATERIAL Y MÉTODOS}

En los diferentes ensayos se utilizaron muestras de leche de tres burras (10-12 días post parto) y tres yeguas (11-15 días post parto), obtenidas de granjas privadas de la Provincia de Tucumán, y leche de dos ejemplares de tapir (10 y 11 días post parto) del Bioparque Temaikén, de Buenos Aires, Argentina. En todos los casos las muestras fueron obtenidas mediante ordeñe manual, sin la utilización de oxitocina como inductor de la lactación. Además, ninguna de las hembras de las tres especies presentaba signos de mastitis.

Todas las muestras correspondían al período maduro de la lactación, etapa en la cual se forma la leche madura, es decir, la secreción producida luego del décimo día de lactación, período en el cual aumenta considerablemente la cantidad de leche que se produce. Las muestras fueron conservadas mediante el agregado de una solución de bicromato de potasio al $1 \%, \mathrm{a}-20^{\circ} \mathrm{C}$ hasta el momento de su estudio.

Para los ensayos de actividad de lisozima en diferentes concentraciones de lactosuero de tapir se utilizó el método turbidimétrico, que mide la lisis de una suspensión de bacterias susceptibles mediante la disminución de la densidad óptica. Se usó una suspensión de Micrococcus luteus (Sigma, MO, USA) en buffer Hepes (ácido 4-(2- hidroxietil)-1-piperazinetan sulfónico) $50 \mathrm{mM} \mathrm{pH} 7,2$ con una densidad óptica inicial de 0,600 y lecturas a 540 nanómetros ${ }^{3}$.

Las reacciones se llevaron a cabo en un espectrofotómetro con arreglo de diodo Hewlett- Packard 8453. Se trabajó con distintas diluciones de lactosuero de tapir, obtenido mediante precipitación ácida de las caseínas a pH 4,3 y posterior centrifugación. Se hicieron diluciones al $50 \% ; 25 \% ; 12,5 \%$ y $6,25 \%$. Cada curva se realizó con $2 \mathrm{ml}$ de suspensión de bacterias y $100 \mu 1$ de lactosuero para cada dilución. En todos los casos se procedió a $25^{\circ} \mathrm{C}$ de temperatura.

Para el ensayo de actividad de lisozima en lactosuero de yegua y burra, las muestras fueron obtenidas a partir de la precipitación ácida de caseínas mediante agregado de buffer acetato de sodio ( $\mathrm{pH} 4,3)$. Estos lactosueros se diluyeron al 1,25\% con buffer Hepes para llevar a cabo la reacción. La misma se realizó con $2 \mathrm{ml}$ de suspensión de M. luteus y $100 \mu 1$ de lactosuero para cada caso. El procedimiento se realizó a $25^{\circ} \mathrm{C}$.

Para la determinación de actividad de lisozima en lactosuero de tapir, yegua y burra a diferentes temperaturas, las muestras fueron sometidas a calentamiento (baño maría) a $40^{\circ} \mathrm{C}, 50^{\circ} \mathrm{C}, 60^{\circ} \mathrm{C}, 70^{\circ} \mathrm{C}$ y $80^{\circ} \mathrm{C}$ durante 30 minutos. Posteriormente fueron centrifugadas y se utilizó el sobrenadante en los ensayos. Como sustrato para la enzima se empleó una suspensión de $M$. luteus a una densidad óptica de 0,600 a $540 \mathrm{~nm}$ de longitud de onda.

Los análisis estadísticos descriptivos incluyeron medidas de tendencia central (media aritmética), dispersión (desvío estándar) y variación (coeficiente de variación), obtenidos utilizando el programa OriginPro 6.1.

\section{RESULTADOS Y DISCUSIÓN}

Los ensayos llevados a cabo demostraron la existencia de actividad de lisozima en la leche de tapir, dato sobre el cual hasta el momento no había registros bibliográficos. Se logró un seguimiento de esta actividad evaluando la lisis microbiana a intervalos variables de tiempo hasta las $2 \mathrm{~h}$ de iniciada la reacción y a diferentes concentraciones.

Como indica la Figura 1, hubo una tendencia a que la actividad de lisozima fuera mayor a largo plazo en muestras más diluidas. Las más concentradas, a los 5 minutos del comienzo de la reacción disminuyeron su actividad, efecto observado también en otras especies

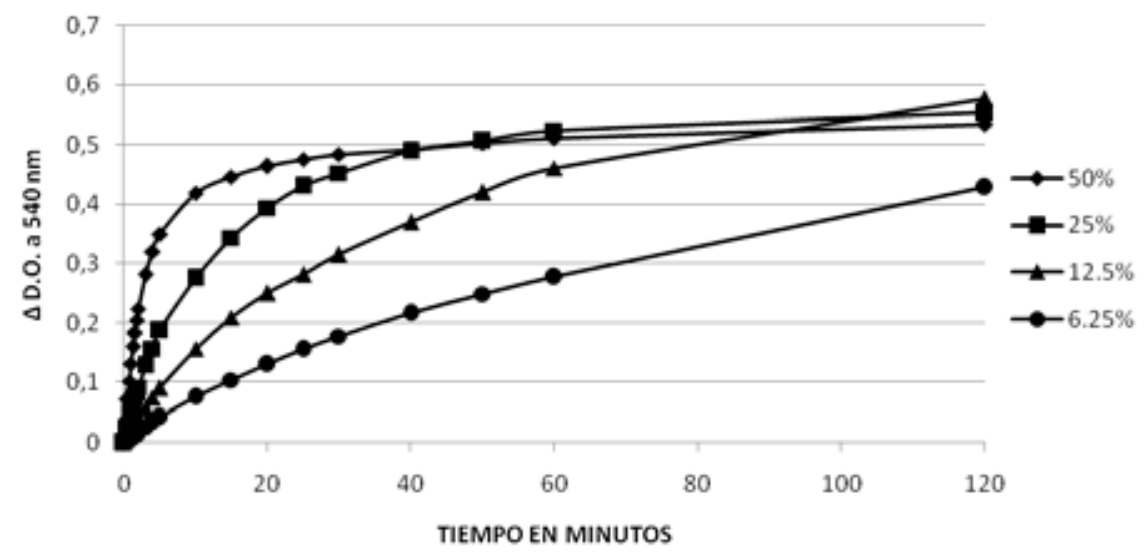

Figura 1. Actividad de lisozima de lactosuero de tapir a diferentes concentraciones. En ningún caso el coeficiente de variación fue superior al $7 \%$. 


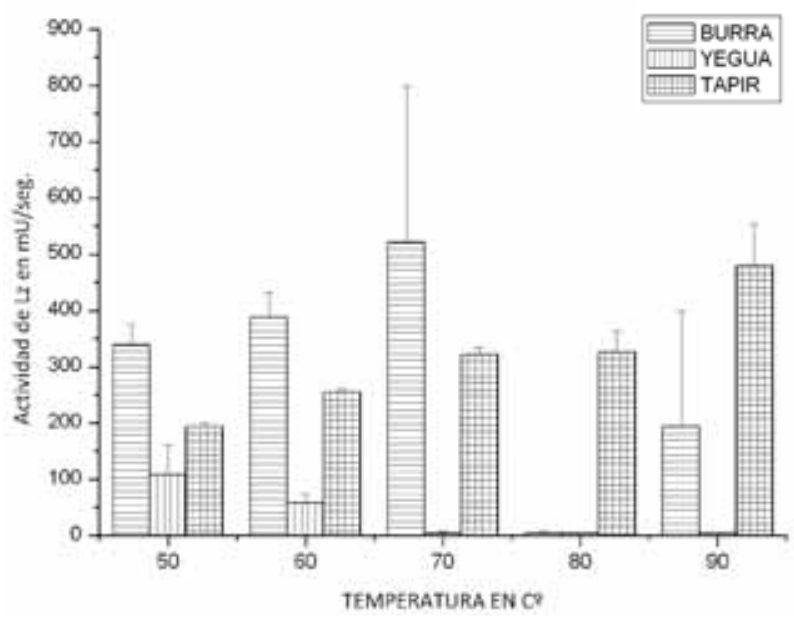

Figura 2. Actividad de lisozima (Lz) en burra, yegua y tapir (mU/seg) a $50,60,70,80$ y $90^{\circ} \mathrm{C}, \overline{\mathrm{x}} \pm \mathrm{SD}$.

estudiadas. Para comparar la actividad de la enzima se tuvieron en cuenta las velocidades iniciales medidas en mili unidades de actividad por segundo (mU/seg). Se encontró que en el tapir esta actividad era mayor a las observadas en leche de mono carayá (Alouatta caraya), elefante marino del sur (Mirounga leonina) y antílope sable (Hippotragus niger) ${ }^{3}$.

$\mathrm{Al}$ efectuar la comparación de la actividad inicial en leche de las tres especies de perisodáctilos a temperatura ambiente, se observó que era mayor en leche de burra (3048,8 $\mathrm{mU} / \mathrm{seg}$ ), seguido por la actividad en leche de yegua $(2916 \mathrm{mU} / \mathrm{seg})$ y finalmente, con valores muchos menores, por la actividad en leche de tapir ( $75,13 \mathrm{mU} / \mathrm{seg})$.

En lo que se refiere a la actividad de la enzima en estas tres especies de perisodáctilos a temperaturas elevadas (Figura 2), se pudo observar que en el caso del lactosuero de yegua hubo un descenso de la actividad enzimática a medida que aumentó la temperatura, llegando inclusive a tornarse nula después de $\operatorname{los} 60^{\circ} \mathrm{C}$. En tapir y burra el comportamiento fue distinto: en ambos casos la actividad no descendió sino que, por el contrario, aumentó con una única disminución a los $80^{\circ} \mathrm{C}$ en el caso de la lisozima de leche de burra, que se restableció a los $90^{\circ} \mathrm{C}$.

En tapir, la máxima actividad se observó a los $90^{\circ} \mathrm{C}$. Este hecho podría compararse con lo que ocurre en la leche humana, donde la actividad de lisozima es más alta a $\operatorname{los} 50^{\circ} \mathrm{C}$ y $70^{\circ} \mathrm{C}$ que a temperatura ambiente, según lo observado en experiencias realizadas en nuestro laboratorio. También en lactosuero humano se había constatado previamente que este aumento de la actividad enzimática es irreversible, incluso hasta 3 horas después de finalizada la exposición al calor.

En base a lo expuesto surge una similitud entre los comportamientos de la leche humana y las de burra y tapir, que conjeturalmente podría deberse a un inhibidor de la lisozima ${ }^{7}$ el cual sería sensible al calor, por lo tanto a temperaturas elevadas se desprendería de la enzima permitiendo una mayor actividad de la misma.
Una vez que la temperatura disminuye este inhibidor no se uniría nuevamente a esta enzima.

La presencia de lisozima en especies vulnerables como el tapir, es importante debido a que la enzima asegura una protección rápida en la cría recién nacida y durante las primeras etapas de su desarrollo. Asimismo su conocimiento representa un aporte novedoso a la fisiología de esta especie, que se enriquece al ser comparada con otros perisodáctilos que constituyen sus parientes vivientes más cercanos.

Agradecimientos. A la M.Sc. Pilar Medina Pereyra por la lectura objetiva de este manuscrito. A la Fundación Miguel Lillo por el financiamiento del trabajo y a la Fundación Temaikén por las muestras proporcionadas.

\section{REFERENCIAS}

1. Businco L, Gianpietro PG, Lucenti P, Lucaroni F, Pini C, Di Felice G. 2000. Allergenicity of mare's milk in children with cow`s milk allergy. J Allergy Clin Immunol 105: 1031-1034.

2. Carroccio A, Cavataio F, Montaldo G, Amico D, Alabrese L, Iacono G. 2000. Intolerance to hydrolyzed cow`s milk protein in infants: Clinical characteristics and dietary treatment. Clin Exp Allergy 30: 1597-1603.

3. Castro F, Rodríguez A, Juárez G, Fernández F. 2009. Aspectos comparativos de la determinación de la actividad lítica de la lisozima. Acta Zool Lilloana 53: 49-56.

4. Chiofalo B, Salimei E, Chiofalo L. 2001. Ass's milk: Explotaition of an alimentary resource. Folium 1: 235-241.

5. Civardi G, Curadi MC, Cattaneo TM, Giangiacomo R. 2002. Capillary electrophoresis applied to analysis of mare's milk. Milchwissenschaft 57: 515-517.

6. Coppola R, Salimei E, Succi M, Sorrentino E, Nanni M, Ranieri P, Belli R, Grazia L. 2002. Behaviour of Lactobacillus rhamnosus strains in ass's milk. Ann Microbiol 52: 55-60.

7. Deckers D, Vanlint D, Callewaert L, Aertsen A, Michiels C. 2008. Role of the lysozyme inhibitor Ivy in growth or survival of Escherichia coli and Pseudomona aerugino$s a$ bacteria in hen egg white and human saliva and breast milk. Appl Environ Microbiol 74: 4434-4439.

8. Doreau M, Martin WM. 2011. Animals that produce dairy foods: Horse. In: Encyclopedia of Dairy Sciences (Fuquay, Fox \& McSweeney Ed.), 2nd edition, Academic Press, San Diego (USA), p. 358-364.

9. Grossowicz N, Ariel M, Weber T. 1979. Improved lysozyme assay in biological fluids. Clin Chem 25: 484-485.

10. Oftedal OT, Jenness R. 1988. Interspecies variation in milk composition among horses, zebras and asses (Perissodactyla: Equidae). J Dairy Res 55: 57-66.

11. Oftedal OT, Iverson SJ. 1995. Comparative analysis of nonhuman milks. In: Handbook of Milk Composition (RG Jensen, ed). Academic Press, San Diego (USA), p. 749-780.

12. Salimei E, Fantuz F, Coppola R, Chiofalo B, Polidori P, Varisco G. 2004. Composition and characteristics of ass's milk. Anim Res 53: 67-78. 